\title{
Microbial and Heavy Metal Contaminants in Herbal Preparations Sold in Maseru, Lesotho
}

\author{
Relebohile Mautsoe*, Taelo Noko, Oriel Hlokoane \\ Department of Pharmacy, Faculty of Health Sciences, National University of Lesotho, Maseru, Lesotho
}

Email address:

relebohilemautsoe@gmail.com (R. Mautsoe)

${ }^{*}$ Corresponding author

\section{To cite this article:}

Relebohile Mautsoe, Taelo Noko, Oriel Hlokoane. Microbial and Heavy Metal Contaminants in Herbal Preparations Sold in Maseru, Lesotho. International Journal of Pharmacy and Chemistry. Vol. 7, No. 4, 2021, pp. 71-79. doi: 10.11648/j.ijpc.20210704.13

Received: July 28, 2021; Accepted: August 10, 2021; Published: August 18, 2021

\begin{abstract}
The majority of the populations, both from developed and developing countries, use herbal preparations for primary healthcare purposes. In particular, the use of herbal preparations in Lesotho is high due to inadequate healthcare facilities and inaccessibility of healthcare services. Herbal preparations are inexpensive, easily accessible and culturally accepted than conventional medicines. Although herbal preparations are popularly used, they could be contaminated with pathogenic microbes, toxic heavy metals and non-metals, agrochemical residues, mycotoxins and endotoxins and, thus World Health Organization (WHO) recommends that herbal preparations should be evaluated for safety, efficacy and potency so as to protect the consumers. This study was, therefore, designed to evaluate heavy metals and microbial contaminants in some of the commercially available herbal preparations in Maseru, Lesotho. A total of five herbal preparations were randomly purchased from different areas of Maseru at market price and were subjected to toxic heavy metals and microbial load analysis in accordance to International pharmacopeia and European pharmacopeia. Antimicrobial sensitivity test was performed to the isolated microorganisms. Our results revealed that all of the five herbal preparations were found to be contaminated with fungi beyond WHO limit, $10^{3} \mathrm{CFU} / \mathrm{ml}$. Pseudomonas aeruginosa was also isolated in all the five herbal preparations. The isolated P. aeruginosa was found to be susceptible to ciprofloxacin and ceftriaxone, clinically used antibiotics. There was no growth of Staphylococcus aureus, Escherichia coli and Klebsiella pneumonia from all the five herbal preparations. Again, total coliform count in three samples exceeded $10^{3} \mathrm{CFU} / \mathrm{ml}$, WHO safety limits. Finally, all herbal preparations complied with the limit test for chlorides; however, only two herbal preparations complied with the limit tests for total heavy metals, less than 20ppm. Therefore, this study reports and concludes that herbal preparations sold in Maseru could be contaminated with pathogenic microorganisms, acid radical's impurities and toxic heavy metal metals. The testing of herbal preparations for microbial and heavy metal contaminants is highly recommended and, may become mandatory.
\end{abstract}

Keywords: Microbial Contaminants, Heavy Metal Contaminants, Herbal Preparations, Antimicrobial Sensitivity, Lesotho

\section{Introduction}

The majority of the populations, both from developed and developing countries, use herbal preparations for primary healthcare purposes [1-3]. The use of herbal preparations is mainly through self-medication [4] and they are available as medicinal preparations, nutraceuticals and cosmetics [5]. It is also reported that $88 \%$ of World Health Organization (WHO) Member States use traditional and complementary medicines [6]. It is estimated that $70-80 \%$ of the population in developing countries, relay on herbal preparations because they are inexpensive, easily accessible, culturally acceptable and sustainable than conventional medicines $[5,7,8]$. Herbal preparations in Lesotho are still viewed as important because of lack of adequate healthcare facilities and inaccessibility of available healthcare services [9]. In rural areas of Lesotho, medicinal plants are the most accessible and affordable form of therapy [10].

Although herbal preparations are considered to be safe [1] and cause no side effects, there have been reports of acute and chronic toxicity resulting from their use [8]. The safety of herbal preparations is still a concern due to contamination by pathogenic microbes, toxic heavy metals and non-metals, agrochemical residues, mycotoxins and endotoxins [11, 12]. 
The contaminants in herbal preparations turn to be carried along from soil where the medicinal plants were grown [5]. The microorganisms adhere to leaves, stems, flowers, seeds, and roots of the medicinal plants used to prepare the herbal products [13]. The microbial contamination of herbal preparations can be caused by unsafe collection, transportation, drying, preparation, improper cleaning procedures or storage [13]. Other sources of contaminants could include the use of unsterile water, handling of preparations with contaminated hands or using contaminated packaging materials $[5,14]$. Some herbalists sell their herbal products by the road side thus exposure to dust could be the possible source of fungal contaminants $[5,15]$. Toxic heavy metals in herbal preparations could be from contaminated water, agricultural methods, manufacturing processes and polluted environment in which the medicinal plants are grown $[16,8]$. Sometimes the use of heavy metals in herbal preparations is intentional, as some of these heavy metals are believed to be beneficial to the human body [7]. Non-essential heavy metals are toxic even in trace amounts [17].

Unlike conventional drugs, herbal preparations are not governed by stringent legislative regulations [5, 7] and therefore could pose health problems to consumers especially if contaminated with heavy metals and pathogenic microbes [1]. Herbal preparations are sometimes classified under dietary supplements and as a result manufacturers sell their herbal preparations without any evidence based scientific study regarding their safety and efficacy [7]. WHO recommends that herbal preparations should be evaluated for efficacy, safety and potency so as to protect the consumers [6]. In Lesotho, several herbal preparations are commercially available but knowledge of their safety with reference to microbial and heavy metal contamination is limited. This study was, therefore, designed to evaluate microbial and heavy metal contamination in some of commercially available herbal preparations in Maseru and the results are communicated in this paper.

\section{Materials and Methods}

The study received the ethical approval from the National University of Lesotho (NUL), Research and Ethics Committee (ID97-2021). The reagents used were of high quality purchased from Prestige laboratory supplies (PTY) Ltd in South Africa and used directly.

\subsection{Study Area and Sample Collection}

A total of five herbal preparations were randomly purchased from herbal medicine retailers in different areas in Maseru at market price on 15 January 2021 and transported to pharmacy laboratory at the National University of Lesotho (NUL) in the same day. The samples purchased were in their original packaging and required no further processing. The purchased herbal preparations were not beyond their expiry date and were intended for oral administration. The samples were assigned unique codes that were used in laboratory analysis and presentation of results [18]. Table 1 summarizes the information of the five herbal preparations.

\subsection{Determination of $\mathrm{pH}$}

The $\mathrm{pH}$ of herbal preparations was determined by using microprocessor $\mathrm{pH}$ meter (model $\mathrm{pH} 50+\mathrm{DSH}^{\circledR}$ purchased in Italy) by following the reported procedure with some modifications [7]. The measurement was done in triplicates and the average $\mathrm{pH}$ was calculated.

Table 1. Composition of the five herbal preparations (HPs), their daily adult dose as indicated on the label and the measured $p H$.

\begin{tabular}{|c|c|c|c|c|}
\hline $\begin{array}{l}\text { Sample } \\
\text { ID }\end{array}$ & $\begin{array}{l}\text { Sample } \\
\text { volume }\end{array}$ & Uses of the preparation as indicated on the label of finished product & $\begin{array}{l}\text { Daily adult dose (70 Kg body } \\
\text { weight) }\end{array}$ & $\mathbf{p H} \pm \mathrm{SD}$ \\
\hline TNHP01 & $1000 \mathrm{ml}$ & $\begin{array}{l}\text { Blood pressure, Arthritis, Cancer, Diabetes, Genital Herpes, Wound infection, } \\
\text { and Sexually transmitted infections (STIs). }\end{array}$ & $\begin{array}{l}\text { About } 50 \mathrm{ml} \text { administered two times } \\
\text { per day }\end{array}$ & $5.85 \pm 0.01$ \\
\hline TNHP02 & $500 \mathrm{ml}$ & Influenza, Respiratory infections and Cold related illnesses. & $\begin{array}{l}\text { About } 80 \mathrm{ml} \text { administered three } \\
\text { times per day (as hot drink) }\end{array}$ & 2 \\
\hline TNHP03 & $1000 \mathrm{ml}$ & $\begin{array}{l}\text { Period pains, Herpes Zoster, Diabetes, Generalized body pains, Haemorrhoids, } \\
\text { Low, Kidney problems, and Chest pains. }\end{array}$ & $\begin{array}{l}\text { About } 30 \mathrm{ml} \text { administered two times } \\
\text { per day }\end{array}$ & $3.84 \pm 0.01$ \\
\hline TNHP04 & $1000 \mathrm{ml}$ & $\begin{array}{l}\text { Joint pains, Arthritis, Fatigue, Inflammation, Myalgia, Period pains, Blood } \\
\text { pressure and Persistent headaches. }\end{array}$ & $\begin{array}{l}\text { About } 30 \mathrm{ml} \text { administered two times } \\
\text { per day }\end{array}$ & $5.39 \pm 0.06$ \\
\hline TNHP05 & $1000 \mathrm{ml}$ & $\begin{array}{l}\text { Wound infections, Blood pressure, Diabetes, Dizziness, Myalgia, Muscle } \\
\text { pains, Muscle pulls, Boils, Tuberculosis (TB), and Arthritis,. }\end{array}$ & $\begin{array}{l}\text { About } 50 \mathrm{ml} \text { administered two times } \\
\text { per day }\end{array}$ & $4.64 \pm 0.02$ \\
\hline
\end{tabular}

\subsection{Determination of Heavy Metals and Non-metals Impurities}

\subsubsection{Limit Test for Heavy Metals}

The $25 \mathrm{ml}$ of the herbal preparation $\mathrm{pH}$ was adjusted to between 3 and 4 using dilute acetic acid or dilute ammonia solution as reported [19]. The solution was then diluted to 35 $\mathrm{ml}$ with distilled water. Freshly prepared $10 \mathrm{ml}$ of hydrogen sulphide solution was added, and the solution was diluted with distilled water to $50 \mathrm{ml}$. The solution was allowed to stand for 5 minutes and thereafter was viewed downwards over a white surface and the colors were recorded. Simultaneously, the same procedure was carried out using 20 ppm standard lead solution. If color produced in sample solution was less than the standard solution (less than 20 ppm), the sample was considered to have passed the limit test of heavy metals. The metallic impurities in substances are expressed as parts of lead per million parts of the substance [19] because lead is one of the most toxic among toxic heavy metals [8]. Metals that respond to this test are lead, mercury, bismuth, arsenic, antimony, tin, cadmium, silver, copper, and molybdenum [19]. 


\subsubsection{Limit Tests for Acid Radical Impurities}

\section{$i$. Limit test for chlorides}

To $1 \mathrm{ml}$ of herbal preparation was added $10 \mathrm{ml}$ of dilute nitric acid and the solution was diluted to $50 \mathrm{ml}$ with distilled water. One milliliter of silver nitrate solution $(5 \% \mathrm{w} / \mathrm{v})$ was added and the solution was stirred immediately with the glass rod. The solution was allowed to stand for 5 minutes and thereafter the opalescence was observed. Simultaneously, the same procedure was carried out using $0.05845 \% \mathrm{w} / \mathrm{v}$ solution of sodium chloride as the standard solution [20]. If opalescence produced in sample solution was less than the standard solution, the sample was considered to have passed the limit test of chlorides [20,21].

\section{ii. Limit test for sulfates}

Two milliliters of dilute hydrochloric acid was added to 1 $\mathrm{ml}$ of herbal preparation and the solution was diluted to $45 \mathrm{ml}$ with distilled water. Five milliliters of barium sulphate reagent was added and the solution was allowed to stand for 5 minutes and thereafter the turbidity was observed. Simultaneously, the same procedure was carried out using $0.1089 \% \mathrm{w} / \mathrm{v}$ solution of potassium sulphates as the standard solution [19]. If turbidity produced in sample solution was less than the standard solution, the sample was considered to have passed the limit test of sulphates $[19,22]$.

\subsection{Microbiological Analyses}

\subsubsection{Media Preparation and Sample Pre-treatment}

The media powder was weighed, reconstituted with distilled water and heated until the media had completely dissolved [12]. The manufacturer's instructions were followed for proper reconstitution of the media [11]. The media was then sterilized by autoclaving at $115 \mathrm{kPa}, 121^{\circ} \mathrm{C}$ for $15 \mathrm{~min}$ [12]. About $15-20 \mathrm{ml}$ the of sterile media was poured into the petri dishes at not more than $45^{\circ} \mathrm{C}$ and allowed to solidify at room temperature [12]. The media was then sealed with parafilm, labelled and stored at between $2-8^{\circ} \mathrm{C}$. The sterility of the prepared media was checked by randomly incubating selected agar plates at $37^{\circ} \mathrm{C}$ for $24 \mathrm{hrs}$ [11].

One millilitres of the sample was dissolved in $9 \mathrm{ml}$ buffered sodium chloride-peptone solution $\mathrm{pH} 7.0$ which was then followed by other tenfold serial dilutions [23] until $10^{-6}$ dilution was achieved.

\subsubsection{Microbial Enumeration Test}

\section{i. Total Aerobic Microbial Count}

The sample was vortexed to ensure uniform distribution of microorganisms if any. One millilitres of the pre-treated sample was spread into the two nutrient agar and incubated at $32^{\circ} \mathrm{C}$ for $48 \mathrm{hrs}$ [1]. Simultaneously, the nutrient agar without an inoculum was incubated as the negative control [23]. The number of colonies formed was counted and the number of cfu per $\mathrm{ml}$ of the sample was calculated.

\section{ii. Total Coliform Count}

The sample was vortexed to ensure uniform distribution of microorganisms if any. One millilitres of the pre-treated sample was spread into two MacConkey agar and incubated at $37^{\circ} \mathrm{C}$ for $24 \mathrm{hrs}$ [1]. Simultaneously, the MacConkey agar without an inoculum was incubated as the negative control [23]. The number of colonies formed was counted and the number of cfu per $\mathrm{ml}$ of the sample was calculated.

\section{iii. Total Combined yeasts/moulds Count}

One milliliters [1] of the pre-treated sample was spread over the surface of Sabouraud-dextrose agar of two petri dishes and incubated at $25^{\circ} \mathrm{C}$ for 5 days [24]. Simultaneously, the Sabouraud-dextrose agar without an inoculum was incubated as the negative control [23]. The number of colonies formed was counted and the number of cfu per $\mathrm{ml}$ of the sample was calculated.

\subsubsection{Test for Specific Microorganisms}

\section{i. Pseudomonas aeruginosa}

One millilitres of the sample was dissolved in $9 \mathrm{ml}$ buffered sodium chloride-peptone solution $\mathrm{pH} 7.0$ [23] and this $10 \mathrm{ml}$ was inoculated in $100 \mathrm{ml}$ casein soya bean digest broth, homogenized and incubated at $35^{\circ} \mathrm{C}$ for $24 \mathrm{hrs}$. Then subculture on a plate of cetrimide agar and incubated at $35^{\circ} \mathrm{C}$ for $24 \mathrm{hrs}[25,26]$. Simultaneously, the cetrimide agar without an inoculum was incubated as the negative control [26]. The growth of colonies was considered to be the presence of Pseudomonas aeruginosa which required to be confirmed by identification tests [25].

\section{ii. Staphylococcus aureus}

One millilitres of the sample was dissolved in $9 \mathrm{ml}$ buffered sodium chloride-peptone solution $\mathrm{pH} 7.0$ [23] and this $10 \mathrm{ml}$ was inoculated in $100 \mathrm{ml}$ casein soya bean digest broth, homogenized and incubated at $35^{\circ} \mathrm{C}$ for $24 \mathrm{hrs}$. Then subculture on a plate of mannitol salt agar and incubated at $35^{\circ} \mathrm{C}$ for $24 \mathrm{hrs}$ [25]. Simultaneously, the mannitol salt agar without an inoculum was incubated as the negative control [26]. The growth of yellow/white colonies surrounded by a yellow zone was considered to be the presence of Staphylococcus aureus which required to beconfirmed by identification tests [25].

iii. Escherichia coli

One millilitres of the sample was dissolved in $9 \mathrm{ml}$ buffered sodium chloride-peptone solution $\mathrm{pH} 7.0$ [23] and this $10 \mathrm{ml}$ was inoculated in $100 \mathrm{ml}$ casein soya bean digest broth, homogenized and incubated at $35^{\circ} \mathrm{C}$ for $24 \mathrm{hrs}$ [25]. The container was shaken and $1 \mathrm{~mL}$ of incubated casein soya bean digest broth was transferred to $100 \mathrm{~mL}$ of MacConkey broth and incubated at $44^{\circ} \mathrm{C}$ for $24 \mathrm{hrs}$. Then subculture on a plate of MacConkey agar at $35^{\circ} \mathrm{C}$ for $24 \mathrm{hrs}[25,26]$. Simultaneously, the MacConkey agar without an inoculum was incubated as the negative control [26]. The growth of colonies was considered to be the presence of Escherichia coli which required to be confirmed by identification tests [25].

\section{iv. Klebsiella pneumonia}

One millilitres of the pre-treated sample was spread into nutrient agar and incubated at $32^{\circ} \mathrm{C}$ for $48 \mathrm{hrs}$ [1]. Simultaneously, the nutrient agar without an inoculum was incubated as the negative control [23]. A pure culture from nutrient agar was inoculated into MacConkey agar and incubated at $33^{\circ} \mathrm{C}$ for $72 \mathrm{hrs}$ [5]. Simultaneously, the 
MacConkey agar without an inoculum was incubated as the negative control [23]. The growth of round mucoid colonies with colourless edges was considered to be the presence of Klebsiella pneumonia which required to beconfirmed by identification tests [5].

\subsection{Disk Diffusion Method for Antibiotic Susceptibility Test}

\subsubsection{Preparation of 0.5 McFarland Standard}

A $0.5 \mathrm{McF}$ arland standard was prepared by adding $0.05 \mathrm{ml}$ of $\mathrm{BaCl}_{2} \cdot 2 \mathrm{H}_{2} \mathrm{O}(1.175 \% \mathrm{w} / \mathrm{v})$ to $9.95 \mathrm{ml}$ of $\mathrm{H}_{2} \mathrm{SO}_{4}(1 \% \mathrm{v} / \mathrm{v})$ with constant stirring. The absorbance of prepared 0.5 McFarland standard was measured at $625 \mathrm{~nm}$ to verify the correct turbidity. The McFarland standard was tightly sealed in the test tube and stored in the dark at room temperature. The McFarland standard was vigorously agitated with the vortex mixer before use [27-29].

\subsubsection{Kirby-Bauer Test Procedure}

Using a sterile inoculating loop, four to five isolated colonies of the organism to be tested was suspended in $2 \mathrm{ml}$ of sterile saline. The saline tube was vortexed to create a smooth microbial suspension and this suspension was compared with 0.5 McFarland standard and adjusted by adding more microorganisms or adding more sterile saline until both 0.5 McFarland standard and microbial suspension had the same turbidity. The plates of Mueller-Hinton agar (MHA) were inoculated by dipping the sterile swabs into the inoculum and streaking the swabs over the surface of MHA three times while rotating the plate through a $60^{\circ}$ angle after each application. The inoculum was left to dry for five minutes at room temperature with the lid closed [27-29].

The antibiotic discs were placed on the inoculated plates using sterile forceps and the plates were incubated at $35^{\circ} \mathrm{C}$ for 18 hours [27-29]. Thereafter, the zones of inhibition were measured using digital vernier calipers and the results were recorded and interpreted as per British Society for Antimicrobial Chemotherapy guidelines on Antimicrobial susceptibility testing [30] and the Clinical \& Laboratory Standards Institute Standards for Antimicrobial Susceptibility Testing [31].

\section{Results}

\subsection{Measurement of pH and Organoleptic Evaluation}

The $\mathrm{pH}$ analysis indicates that the herbal preparations had the $\mathrm{pH}$ range of $3.84 \pm 0.01$ to $5.86 \pm 0.02$. Four $(80 \%)$ of the samples had no color change after 39 days from the day of purchases while one sample (TNHP04) showed color change. All the samples were redispersible with small amount of agitation.

\subsection{Heavy Metals and Non-metals Impurities}

Table 2 shows the results for heavy metals and non-metals analysis. All the samples have passed the limits test for chlorides and sulphates except one sample (TNHP03) which failed the limit test for sulphates. Out of the five herbal preparations, only two (TNHP02 and TNHP05) had total heavy metals less than $20 \mathrm{ppm}$.

Table 2. Limit tests for total heavy metals and acid radical impurities.

\begin{tabular}{llll}
\hline \multirow{2}{*}{ Sample ID } & \multicolumn{2}{l}{ Limit tests for acid radical impurities } & Limit tests for metallic impurities \\
\cline { 2 - 4 } & Chlorides & Sulphates & Total Heavy metals in parts per million (ppm) \\
\hline TNHP01 & Pass & Pass & $>20$ \\
TNHP02 & Pass & Pass & $<20$ \\
TNHP03 & Pass & Fail & $>20$ \\
TNHP04 & Pass & Pass & $>20$ \\
TNHP05 & Pass & Pass & $<20$ \\
\hline
\end{tabular}

\subsection{Microbial Analysis}

Table 3 shows the results for microbial enumeration tests. Three $(60 \%)$ herbal preparations exceeded the total aerobic microbial count safety limits, one $(20 \%)$ herbal preparation (TNHP03) was at marginal level and one (20\%) herbal preparation (TNHP05) was within the safety limits (table 3 and table 4). Total coliform count was found in three samples (TNHP01, TNHP02 and TNHP04) where they exceeded the safety limit (table 3 and table 4). All the five herbal preparations exceed the safety limit for total combined yeasts/moulds count as reflected in (table 3 and table 4).

Table 3. Microbial enumeration tests for herbal preparations.

\begin{tabular}{llll}
\hline Sample ID & Total Aerobic Microbial Count (CFU/ml) & Total Coliform Count (CFU/ml) & Total Combined yeasts/moulds Count (CFU/ml) \\
\hline TNHP01 & $2.7 \times 10^{6}$ & $1.72 \times 10^{6}$ & $3 \times 10^{6}$ \\
TNHP02 & $1.49 \times 10^{6}$ & $7 \times 10^{5}$ & $3 \times 10^{6}$ \\
TNHP03 & $4.04 \times 10^{5}$ & Negative & $6 \times 10^{8}$ \\
TNHP04 & $3.6 \times 10^{8}$ & $9.1 \times 10^{5}$ & $4.9 \times 10^{5}$ \\
TNHP05 & $5.6 \times 10^{4}$ & Negative & $2.66 \times 10^{6}$ \\
\hline
\end{tabular}


Table 4. AHPA Recommended Microbial Limits for 'Finished'Botanical Preparations.

\begin{tabular}{lll}
\hline Organization & EP category C & WHO \\
\hline Product & Herbal medicinal products that have failed category B (CFU/ml) & Plant materials for internal use (CFU/ml) \\
\hline Total aerobic microbial count & $10^{5}$ & $10^{5}$ \\
Total combined yeast \& mold count & $10^{4}$ & $10^{3}$ \\
Bile-tolerant Gram- negative bacteria & $10^{4}$ & $10^{3}$ except E. coli \\
Escherichia coli & Absence in $1 \mathrm{ml}$ & $10 \mathrm{in} 1 \mathrm{ml}$ \\
Pseudomonas aeruginosa & Not Assigned & Absent \\
Staphylococcus aureus & Not Assigned & Absent \\
\hline
\end{tabular}

AHPA - American Herbal Preparations Association Guidance, 8630 Fenton St. \#918, Silver Spring, MD 20910; 301-588-1171

EP: European Pharmacopoeia Edition 8.0, 5.1.8, 2013.

WHO - World Health Organization, Quality control methods for medicinal plant materials, Geneva, 1998

Table 5 shows the results for tests for specified microorganism in herbal preparations. As reflected in table 5, there was no growth of Staphylococcus aureus, Klebsiella pneumonia and Escherichia coli in all herbal preparations. In contrast, all the five herbal preparations had Pseudomonas aeruginosa.

Table 5. Tests for specified microorganism in herbal preparations.

\begin{tabular}{llll}
\hline Sample ID & Staphylococcus aureus & Pseudomonas aeruginosa & Escherichia coli \\
\hline TNHP01 & Negative & Positive & Negative \\
TNHP02 & Negative & Positive & Negative \\
TNHP03 & Negative & Positive & Negative \\
TNHP04 & Negative & Nositive & Negative \\
TNHP05 & Negative & Positive & Negative \\
\hline
\end{tabular}

\subsection{Disk Diffusion Method for Antibiotic Susceptibility Test}

Figure 1 shows some of the results for drug susceptibility tests of Pseudomonas aeruginosa, unidentified aerobic microorganisms, unidentified coliforms and unidentified yeasts/moulds. Only Pseudomonas aeruginosa was isolated from all the five herbal preparations. There were zones of inhibition in Pseudomonas aeruginosa, unidentified aerobic microorganisms and unidentified coliforms where ciprofloxacin and ceftriaxone were used. Some of the unidentified aerobic microorganisms and unidentified coliforms showed no zones of inhibition against test antibiotics as summarized in table 6 . Table 7 shows the drug sensitivity pattern of microorganisms against the different antibiotics. All the five herbal preparations contained unidentified yeasts/moulds which showed no zone of inhibition on nystatin. There were also no zones of inhibition for Amoxicillin $25 \mu \mathrm{g}$, Erythromycin $15 \mu \mathrm{g}$, Vancomycin $30 \mu \mathrm{g}$ and Nalidixic acid $30 \mu \mathrm{g}$ in some of the unidentified aerobic microorganisms and unidentified coliforms.

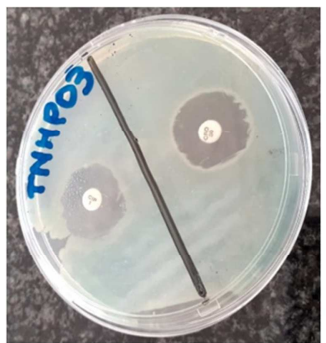

(a)

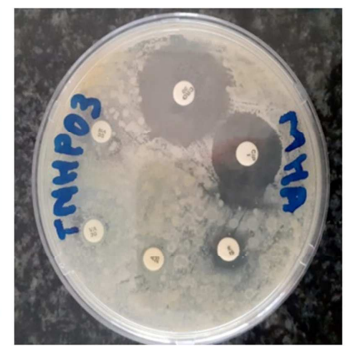

(b)

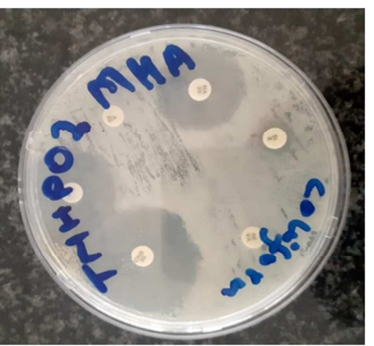

(c)

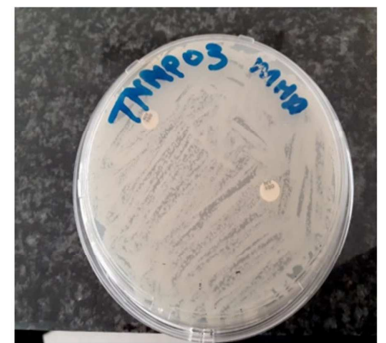

(d)

Figure 1. Drug susceptibility tests of Pseudomonas aeruginosa and unidentified microorganisms. (a) Observation of diameter zones of inhibition for Pseudomonas aeruginosa in TNHP03, (b) diameter zones of inhibition for unidentified aerobic microorganism in TNHP03, (c) diameter zones of inhibition for unidentified coliforms TNHP02 and (d) diameter zones of inhibition for unidentified yeast/mold count in TNHP03.

Table 6. Antimicrobial susceptibility of microorganisms.

\begin{tabular}{|c|c|c|c|c|c|c|c|c|}
\hline \multirow{2}{*}{ Sample ID } & \multirow{2}{*}{ Microorganism from each sample } & \multicolumn{7}{|c|}{ Diameter of zones of inhibition (mm) } \\
\hline & & $\mathbf{A 2 5}$ & E15 & VA30 & CIP1 & CRO30 & NA30 & NY100 \\
\hline \multirow{4}{*}{ TNHP01 } & Pseudomonas aeruginosa & - & - & - & 30.65 & 32.30 & - & - \\
\hline & Unidentified aerobic microorganisms & Negative & 10.17 & Negative & 32.42 & 29.64 & Negative & - \\
\hline & Unidentified coliforms & Negative & Negative & Negative & 29.98 & 32.44 & 24.98 & - \\
\hline & Unidentified yeasts/moulds & - & - & - & - & - & - & Negative \\
\hline \multirow{4}{*}{ TNHP02 } & Pseudomonas aeruginosa & - & - & - & 30.30 & 30.18 & - & - \\
\hline & Unidentified aerobic microorganisms & 20.21 & 11.83 & Negative & 20.59 & 26.36 & Negative & - \\
\hline & Unidentified coliforms & Negative & Negative & Negative & 26.35 & 28.34 & 22.52 & - \\
\hline & Unidentified yeasts/moulds & - & - & - & - & - & - & Negative \\
\hline
\end{tabular}




\begin{tabular}{|c|c|c|c|c|c|c|c|c|}
\hline \multirow{2}{*}{ Sample ID } & \multirow{2}{*}{ Microorganism from each sample } & \multicolumn{7}{|c|}{ Diameter of zones of inhibition (mm) } \\
\hline & & $\mathbf{A 2 5}$ & E15 & VA30 & CIP1 & CRO30 & NA30 & NY100 \\
\hline \multirow{3}{*}{ TNHP03 } & Pseudomonas aeruginosa & - & - & - & 21.10 & 22.28 & - & - \\
\hline & Unidentified aerobic microorganisms & Negative & 10.39 & Negative & 28.26 & 21.25 & Negative & - \\
\hline & Unidentified yeasts/moulds & - & - & - & - & - & - & Negative \\
\hline \multirow{4}{*}{ TNHP04 } & Pseudomonas aeruginosa & - & - & - & 31.70 & 27.07 & - & - \\
\hline & Unidentified aerobic microorganisms & Negative & Negative & Negative & 34.06 & 31.80 & 26.54 & - \\
\hline & Unidentified coliforms & Negative & Negative & Negative & - & 21.4 & 22.68 & - \\
\hline & Unidentified yeasts/moulds & - & - & - & - & - & - & Negative \\
\hline \multirow{3}{*}{ TNHP05 } & Pseudomonas aeruginosa & - & - & - & 27.14 & 30.95 & - & - \\
\hline & Unidentified aerobic microorganisms & 28.15 & 19.46 & 34.48 & 23.00 & 25.74 & Negative & - \\
\hline & Unidentified yeasts/moulds & - & - & - & - & - & - & Negative \\
\hline
\end{tabular}

Key: CIP1=Ciprofloxacin $1 \mu \mathrm{g}$; CRO30=Ceftriaxone $30 \mu \mathrm{g}$; A25=Amoxicillin 25 $\mu \mathrm{g}$; E15=Erythromycin 15 $\mu \mathrm{g}$; VA30=Vancomycin 30 $\mu$ g; NA30=Nalidixic acid $30 \mu \mathrm{g}$; NY100=Nystatin 100 units

$-=$ Test not done/Not studied

Table 7. Drug sensitivity pattern of microorganisms against the antibiotics.

\begin{tabular}{|c|c|c|c|c|}
\hline \multirow{2}{*}{ Sample ID } & \multirow{2}{*}{ Microorganism from each sample } & \multirow{2}{*}{$\begin{array}{l}\text { Sensitivity test } \\
\text { Susceptible }\end{array}$} & \multirow{2}{*}{ No zones of inhibition observed* } & \multirow{2}{*}{ zones of inhibition observed $* *$} \\
\hline & & & & \\
\hline \multirow{4}{*}{ TNHP01 } & Pseudomonas aeruginosa & CIP1, CRO30 & - & - \\
\hline & Unidentified aerobic microorganisms & - & A25, VA30, NA30 & E15, CIP1, CRO30 \\
\hline & Unidentified coliforms & - & $\mathrm{A} 25, \mathrm{E} 15, \mathrm{VA} 30$ & CIP1, CRO30, NA30 \\
\hline & Unidentified yeasts/moulds & - & NY100 & - \\
\hline \multirow{4}{*}{ TNHP02 } & Pseudomonas aeruginosa & CIP1, CRO30 & - & - \\
\hline & Unidentified aerobic microorganisms & - & VA30, NA30 & A25, E15, CIP1, CRO30 \\
\hline & Unidentified coliforms & - & $\mathrm{A} 25, \mathrm{E} 15, \mathrm{VA} 30$ & CIP1, CRO30, NA30 \\
\hline & Unidentified yeasts/moulds & - & NY100 & - \\
\hline \multirow{3}{*}{ TNHP03 } & Pseudomonas aeruginosa & CIP1, CRO30 & - & - \\
\hline & Unidentified aerobic microorganisms & - & A25, VA30, NA30 & E15, CIP1, CRO30 \\
\hline & Unidentified yeasts/moulds & - & NY100 & - \\
\hline \multirow{4}{*}{ TNHP04 } & Pseudomonas aeruginosa & CIP1, CRO30 & - & - \\
\hline & Unidentified aerobic microorganisms & - & $\mathrm{A} 25, \mathrm{E} 15, \mathrm{VA} 30$ & CIP1, CRO30, NA30 \\
\hline & Unidentified coliforms & - & $\mathrm{A} 25, \mathrm{E} 15, \mathrm{VA} 30$ & CRO30, NA30 \\
\hline & Unidentified yeasts/moulds & - & NY100 & - \\
\hline \multirow{3}{*}{ TNHP05 } & Pseudomonas aeruginosa & CIP1, CRO30 & - & - \\
\hline & Unidentified aerobic microorganisms & - & NA30 & $\mathrm{A} 25, \mathrm{E} 15, \mathrm{VA30}, \mathrm{CIP} 1, \mathrm{CRO} 30, \mathrm{NA} 30$ \\
\hline & Unidentified yeasts/moulds & - & NY100 & - \\
\hline
\end{tabular}

Key: CIP1=Ciprofloxacin 1 $\mu \mathrm{g}$; CRO30=Ceftriaxone $30 \mu \mathrm{g}$; A25=Amoxicillin $25 \mu \mathrm{g}$; E15=Erythromycin 15 $\mu \mathrm{g}$; VA30=Vancomycin 30 $\mu \mathrm{g}$; NA30=Nalidixic acid $30 \mu \mathrm{g} ; \mathrm{NY} 100=$ Nystatin 100 units

*There was no diameter zone of inhibition on a particular antibiotic but since the microorganism was unidentified, results do not tell if the unidentified microorganisms were resistant or the antibiotic was not suitable for those unidentified microorganisms.

**There was diameter zone of inhibition on a particular antibiotic but since the microorganism was unidentified, the results to do not tell if those microorganisms are susceptible, intermediate or resistant to antibiotic

$-=$ Test not done/Not studied

\section{Discussion}

The $\mathrm{pH}$ analysis indicates that three samples were within the required $\mathrm{pH}$ range for oral medicines of 5 to 8 [7]. One sample showed color change after 39 days of purchases which is an evidence of physical instability. A color change in oral suspension may indicate chemical degradation or microbial contamination [32]. All the suspensions were redispersible with small amount of agitation and this ensures uniform concentration of solutes upon administration.

The results obtained elucidate that three herbal preparations had higher content of heavy metals. The general limit for heavy metals in the United States Pharmacopeia (USP) and European Pharmacopeia (EP) is 10 ppm or 20 ppm [33, 34]. Metals that respond to limit test for heavy metals are lead, mercury, bismuth, arsenic, antimony, tin, cadmium, silver, copper, and molybdenum [19]. However, the limit test is not sensitive enough to detect low concentrations of heavy metals and does not reveal which heavy metal is above the recommended limit. Therefore, these herbal preparations can potentially cause heavy metal toxicity to consumers $[1,8]$. Although two herbal preparations were found to be within permissible limits for total heavy metals, the safety of these herbal preparations cannot be guaranteed as permissible daily exposures for the heavy metals could be exceeded because the consumption of the heavy metals is directly proportional to the dose of the herbal preparations [8].

The results show that all the five herbal preparations comply with requirements for limit test for chlorides [20, 21] as all the samples were less opalescent than the prepared sodium chloride standard solution. One herbal preparation was more turbid than the prepared standard potassium sulphate solution thus indicating that it did not pass the limit test for sulphates [19, 22]. Chlorides and sulphates are acid radical impurities and generally arise from the use of tap water 
in manufacturing processes [20]. Chlorides could get into surface water from several sources including; rocks as they contain chlorides, agricultural run-off, waste water from industries, oil well wastes, and effluent waste water from waste water treatment plants [35]. Sulphates find way into water possibly due to natural sources as well as anthropogenic sources [36]. The presence of impurities such as chlorides and sulphates affect the efficacy and safety of herbal products.

Microbial analyses revealed that total coliform count was beyond limits in three samples. Coliforms indicate faecal contamination [13] which means the herbal preparations may have been directly or indirectly contaminated by human or animal faecal matter [38]. The detection of coliforms may also indicate the presence of pathogenic bacteria such as Salmonella spp [5, 39]. Coliforms are the major cause of waterborne and foodborne diseases which may cause intestinal tract infections to consumers $[13,37]$. The herbal preparations which contain coliforms are therefore not suitable for human consumption [38].

The detection of pathogenic gram negative bacteria, $P$. aeruginosa, in all the five samples was of concern. $P$. aeruginosa is expected to be absent in herbal preparations [5] and its presence indicates health risk associated with the use of these products. $P$. aeruginosa was also detected in one study that evaluated microbial contaminants of herbal preparations [38]. The presence of both total aerobic microbial count beyond limits and $P$. aeruginosa could indicate poor hygiene conditions in the preparation or storage of these herbal preparations $[5,13]$. The fungi that exceed WHO recommended limits suggested that the herbal preparations might also contained mycotoxins [15], which when ingested may cause illness or human death [40].

The microbial contaminants in these herbal preparations were probably caused by unsafe collection, transportation, drying, preparation, improper cleaning procedures or storage [13]. Other sources of contamination could be the use of unsterile water, handling of preparations with contaminated hands or using contaminated packaging materials [5, 14]. Some herbalists sell their preparations by the road side thus exposure to dust might be the possible source of fungal contaminations $[5,15]$. One or some of these sources of herbal preparation contaminations could have affected the microbial quality of the final finished product. This study is in agreement with previous studies $[1,11]$ in that both studies did not detect Klebsiella pneumonia, Escherichia coli and Staphylococcus aureus in herbal preparations.

Antibiotic susceptibility studies on the herbal preparations indicated that the isolated $P$. aeruginosa was susceptible to ciprofloxacin and ceftriaxone. However, the herbal preparations contained unidentified yeast/moulds, unidentified aerobic bacteria and unidentified coliforms upon which there were no zones of inhibition to some antibiotics tested. Although there were no zones of inhibition on amoxicillin, erythromycin, nalidaxic acid, nystatin and vancomycin, it could not be concluded as to whether the unidentified microorganisms were resistant or the antibiotic was not suitable for those unidentified microorganisms. On the other hand, no zone of inhibition on amoxicillin, erythromycin, nalidaxic acid and vancomycin may suggest emerging multidrug resistance. One study recovered multidrug resistant bacteria from herbal preparations in southern Nigerian [41]. The study also showed that there was diameter zone of inhibition on some antibiotics but since the microorganism was unidentified, the results could not tell whether those microorganisms are susceptible or intermediate or resistant to antibiotics tested. The herbal preparations in this study are commercially sold to children less than five years, healthy and sick people including cancer, HIV/AIDS and patients on immunosuppressants hence the use of contaminated herbal preparations can cause serious health hazard.

\section{Recommendations}

The future studies should focus on quantitative analysis of heavy metals in herbal preparation so as to determine daily intake limit of heavy metals. Again, studies to isolate and characterize microorganisms from herbal preparations and determine their resistance patterns to antibiotics are recommended. The manufacturers are advised to adhere to WHO guidelines on good manufacturing practices (GMP) for herbal medicines or subject their finished herbal products to standardization of herbal medicines so as to maintain correct quality, safety and efficacy of the final herbal preparations.

\section{Conclusion}

This study concludes and reports that herbal preparations sold in Maseru could be contaminated with microorganisms, some of which are pathogenic. The study also showed that the herbal preparations could contain acid radicals and heavy metal impurities, or maybe of $\mathrm{pH}$ that is outside the required $\mathrm{pH}$ range. Based on the results, there is a need to enforce standardization of herbal preparations before consumption. The manufacture of herbal preparations for commercial use should be monitored from beginning to final products to ensure that they are produced in accordance to WHO guidelines on good manufacturing practices for herbal medicines and thus reduce the risks to consumers. Therefore, testing of herbal preparations for microbial and heavy metal contaminants is highly recommended and, may become mandatory.

\section{Conflict of Interest Statement}

The authors declare that they have no competing interests.

\section{Acknowledgements}

The financial support from the government of Lesotho through the National Manpower Development Secretariat (NMDS) is gratefully acknowledged by Taelo Noko. Department of Pharmacy at NUL is thanked by all authors for providing access to laboratory space and equipment. 


\section{References}

[1] Turkson, B. K., Mensah, M. L. K., Sam, G. H., Mensah, A. Y., Amponsah, I. K., Ekuadzi, E., Komlaga, G., \& Achaab, E. (2020). Evaluation of the Microbial Load and Heavy Metal Content of Two Polyherbal Antimalarial Products on the Ghanaian Market. Evidence-based Complementary and Alternative Medicine, 2020, 1-5.

[2] Oyebode O, Kandala NB, Chilton PJ, \& Lilford, R. J. (2016). Use of traditional medicine in middle-income countries: A WHO-SAGE study. Health Policy and Planning, 31, 984-991.

[3] O. M. S. (2013). Traditional medicine EXECUTIVE BOARD 134th session Provisional agenda item 9.1. Eb134/24 2013, 14.

[4] Vaikosen, E. N., \& Alade, G. O. (2017). Determination of heavy metals in medicinal plants from the wild and cultivated garden in Wilberforce Island, Niger Delta region, Nigeria. Journal of Pharmacy and Pharmacognosy Research, 5, 129143.

[5] Keter, L., Too, R., Mwikwabe, N., Ndwigah, S., Orwa, J., Mwamburi, E., Korir, R., \& Mutai, C. (2016). Bacteria Contaminants and their Antibiotic Sensitivity from Selected Herbal Medicinal Products from Eldoret and Mombasa, Kenya. American Journal of Microbiology, 7, 18-28.

[6] World Health Organization. (2007). Guidelines for Assessing Quality of Herbal Medicines with Reference to Contaminant and Residue. Geneva, Switzerland. Epub ahead of print 2007. https://doi.org/10.16309/j.cnki.issn.1007-1776.2003.03.004.

[7] Zamir, R., Hosen, A., Ullah, M. O., \& Nahar, N. (2015). Microbial and heavy metal contaminant of antidiabetic herbal preparations formulated in Bangladesh. Evidence-based Complementary and Alternative Medicine, 2015, 1-9.

[8] Saeed, M., Muhammad, N., Khan, H. \& Zakiullah. (2011). Assessment of heavy metal content of branded Pakistani herbal products. Tropical Journal of Pharmaceutical Research, 10 (4): 499-506.

[9] Moteetee, A., \& Seleteng Kose, L. (2016). Medicinal plants used in Lesotho for treatment of reproductive and post reproductive problems. Journal of Ethnopharmacology, 194, 827-849.

[10] Hlokoane, O. K., \& Sello, M. (2021). Antimicrobial wound healing properties of indigenous medicinal plants of Lesotho and the pharmacist's role in minor wound care. South African Pharmaceutical Journal, 88 (1): 33a-33e.

[11] Abba, D., Inabo, H. I., Yakubu, S. E. \& Olonitola, O. S. (2009) Contamination of herbal medicinal products marketed in Kaduna metropolis with selected pathogenic bacteria. African Journal of Traditional, Complementary and Alternative Medicines, 6 (1): 70-77.

[12] Onyambu, M. O., Chepkwony, H. K., Thoithi, G. N,. Ouya, G. O., \& Osanjo, G. O. (2013). Microbial Quality of Unregulated Herbal Medicinal Products in Kenya. African Journal of Pharmacology and Therapeutics, 2 (3): 70-75.

[13] de Sousa Lima, C. M., Fujishima, M. A. T., de Paula Lima, B. Mastroianni, P. C., de Sousa, F. F. O., \& da Silva, J. O. (2020). Microbial contamination in herbal medicines: a serious health hazard to elderly consumers. BMC Complementary Medicine and Therapies, 20 (1): 1-9.
[14] Wylie, J. L., \& Nowicki, D. L. (2005). Molecular epidemiology of community- and health care-associated methicillin-resistant Staphylococcus aureus in Manitoba, Canada. Journal of Clinical Microbiology, 43, 2830-2836.

[15] Ashiq, S., Hussain, M., \& Ahmad, B. (2014). Natural occurrence of mycotoxins in medicinal plants: A review. Fungal Genetics and Biology, 66, 1-10.

[16] Ekeanyanwu, R. C., Njoku, J. O., Nwodu, P. O., \& Njokuobi, A. E. (2013). Analysis of some selected toxic heavy metals in some branded nigerian herbal products. Journal of Applied Pharmaceutical Science, 3 (4): 088-091.

[17] Maobe, M., Gatebe, E., Gitu, L., \& Rotich, H. (2012). Profile of heavy metals in selected medicinal plants used for the treatment of diabetes, malaria and pneumonia in Kisii Region, Southwest Kenya. Global Journal of pharmacology, 6 (3): 245-251.

[18] Keter, L., Too, R., Mwikwabe, N., Mutai, C., Orwa, J., Mwamburi, L., Ndwigah, S., Bii, C., \& Korir, R. (2017). Risk of Fungi Associated with Aflatoxin and Fumonisin in Medicinal Herbal Products in the Kenyan Market. Scientific World Journal, 2017, 1-6.

[19] Ahmed, H., Ehtesham, M., Rasheed, N., \& Mohammad, A. S. (2017). Pharmaceutical Importance and Significance of Limit Tests. Asian Journal of Pharmaceutical Research, 7 (1): 30 34.

[20] Kar, A. (2005). Pharmaceutical Drug Analysis. second edi. New Delhi: New Age International (P) Ltd., Publishers, 2005. Epub ahead of print 2005. https://doi.org/10.16309/j.cnki.issn.1007-1776.2003.03.004.

[21] The International Pharmacopoeia. (2020). 2.2.1 Limit test for chlorides. The International Pharmacopoeia - Ninth Edition 2020 .

[22] Pharmacopoeia TI. (2017). 2.2.2 Limit test for sulfates. The International Pharmacopoeia - Ninth Edition 2020.

[23] European Pharmacopoeia. (2005). 2.6.12. Examination of Non-Sterile Products (Total Viable Aerobic Count). European Pharmacopoeia, 11-12.

[24] The International Pharmacopoeia. 3.3.1 Microbial enumeration tests. In: The International Pharmacopoeia Ninth Edition, 1-7.

[25] The International Pharmacopoeia. 3.3.2 Tests for specified microorganisms. In: The International Pharmacopoeia - Ninth Edition, 1-9.

[26] European Pharmacopoiea. (2010). 2.6.13. Examination of Non-Sterile Products: Test for Specified. Test, 167-171.

[27] Dalynn Biologicals. (2014). McFarland Standard. McFarland Standards for in Vitro Use Only, 2.

[28] Wootton, M. (2013). BSAC Methods for Antimicrobial Susceptibility Testing. British Society for Antimicrobial Chemotherapy, 44, 1-87.

[29] Hudzicki, J. (2012). Kirby-Bauer Disk Diffusion Susceptibility Test Protocol Author Information. American Society for Microbiology, 1-13.

[30] British Society for Antimicrobial Chemotherapy. (2020). The Grants Register, 221-221. 
[31] CLSI. (2019). CLSI Standards for Antimicrobial Susceptibility Testing (AST). Journal of Enam Medical College, 6, 15-18.

[32] The International Pharmacopoeia. (2020). Liquid preparations for oral use. 1-4.

[33] Raghuram, P., Soma Raju, I. V., \& Sriramulu, J. (2010). Heavy metals testing in active pharmaceutical ingredients: An alternate approach. Pharmazie; 65 (1): 15-18.

[34] Reddy, M. M., Reddy, K. H., \& Reddy, M. U. (2016). Harmonized Guideline on Limit and Testing of Elemental Impurities in Pharmaceutical Substances: A Review. Pharmaceut Reg Affairs, 2016, 5: 2.

[35] Kumar, M., \& Puri, A. (2012). A review of permissible limits of drinking water. Indian journal of occupational and environmental medicine, 16 (1): 40-44.

[36] Venkatesan, G., \& Swaminathan, G. (2009). Review of Chloride and Sulphate Attenuation in Ground Water nearby Solid-Waste Landfill Sites. Journal of Environmental Engineering and Landscape Management, 17 (1): la-lg.

[37] Ogunshe A. A. O., Fasola, T. R., \& Egunyomi, A. (2006).
Bacterial profiles and consumer preference of some indigenous orally consumed herbal medications in Nigeria. Journal of Rural and Tropical Public Health, 5, 27-33.

[38] Esimone, C. O., Oleghe, P. O., Ibezim, E. C., Okeh, C. O., \& Iroha, I. R. (2007). Susceptibility-resistance profile of micro-organisms isolated from herbal medicine products sold in Nigeria. African Journal of Biotechnology, 6 (24): 27662775 .

[39] Forest, J. (2004). Faecal Coliforms. University of Iowa Hygienic Laboratory Manual, 36, 2-4.

[40] Alshannaq, A., Yu, J-H., Cano-Sancho, G., Sanchis, V., Marín, S., Ramos, A. J., Pitt, J. I., Wild, C. P., Baan, R. A., Gelderblom, W. C. A., Miller, J. D., Riley, R. T., \& Wu, F. (2012). Improving public health through mycotoxin control. Lyon, France: International Agency for Research on Cancer (IARC Scientific Publications Series, No. 158). Food and Chemical Toxicology; 51 (1): 188-193.

[41] Omoikhudu, O. P., Odimegwu, D. C., Udofia, E., Esimone, C. O. (2011). Multi-drug-resistant bacteria isolates recovered from herbal medicinal preparations in a Southern Nigerian setting. Journal of Rural and Tropical Public Health, 10, 7075 . 